\title{
Spectrum of Breast Diseases in Females- a 10 years study
}

\author{
Ahmed S $^{1}$,Ahmed S ${ }^{2}$, Ahmed N ${ }^{3}$, Aziz NMSB ${ }^{4}$
}

Conflicts Of Interest: The authors indicate no potential conflicts of interest.

Received: 18 April 2017 Accepted: 22 May 2017 www.banglajol.info/index.php/JSSMC
Key words: Spectrum, Breast disease, Benign Breast Disease (BBD).

\begin{abstract}
:
Objective: To determine the frequency of various breast diseases in female patients.

Methodology: This is a prospective (historical)cohort study of female patients from 18 to 55 years of age visiting a female surgeon with breast problems. The study was conducted at Chittagong Metropoliton Hospital and CSCR Hospital in Chittagong over a period of 10 years starting from July 2007 to June 2017. All female patients visiting with breast problems were included in the study, excluding the patients of below 18 years and above 55 years. The findings were tabulated in excel sheet and analyzed for the frequency of each lesion.
\end{abstract}

Results: A total of 3555 patients were included in the study. Benign breast disease (BBD) was much more common than the malignant breast disease which was 3.49\% (124/3555) of all breast diseases. Fibroadenoma was the most common benign breast disease, seen in $32.26 \%(1147 / 3555)$ of patients followed by mastalgia, seen in $24.22 \%(861)$ patients. The next common breast disease is fibrocystic change in $18.80 \%(668 / 3555)$ patients.

Conclusion: Breast diseases, both benign and malignant are the common problems of female. But benign breast diseases are much more common than the malignant diseases. Fibroadenoma is the commonest of all benign breast diseases in our set up. Mastalgia and fibrocystic changes are the next two common diseases.

[J Shaheed Suhrawardy Med Coll 2017; 9(1): 10-12] DOI: http://dx.doi.org/10.3329/jssmc.v9i1.37252

\section{Introduction:}

Breast is a dynamic organ which undergoes cyclical changes under the influence of hormones and growth factors throughout the reproductive life of a woman--1. The vast majority of the breast lesions are benign and far commoner than the malignant one, but they are not given significant attention as compared to malignant one. The significance of this entity is that around $50 \%$ of women in their life time would have had the sign or symptom of benign breast disease2. Both the physical and specially the psychological sufferings of those females should not be underestimated and must be taken care of. In fact some benign breast lesions can be a predisposing risk factor for developing malignancy in later part of life2,3. So it is

1. Dr. Shakera Ahmed, Assistant Professor, Department of Surgery, Chittagong Medical College, Chittagong

2. Dr. Sami Ahmad, Associate Professor, Department of Surgery, Shaheed Suhrawardy Medical College \& Hospital

3. Dr. Nadim Ahmed, Senior Consultant, Department of Surgery, Shaheed Suhrawardy Medical College \& Hospital

4. Dr. Nur Mohommad Sayed Bin Aziz, Junior Consultant, Department of Surgery, Shaheed Suhrawardy Medical College \& Hospital

Correspondence to: Dr. Shakera Ahmed, Assistant Professor, Department of Surgery, Chittagong Medical College, Email: shakeraahmed12@gmail.com Mobile no: 01711307876. essential to recognize and study these lesions in detail to identify the high risk group of patients and providing regular surveillance can lead to early detection and management of malignancy. As the study includes a great number of patients, this may reflect the spectrum of breast diseases among females in Bangladesh.

Aims and Objectives: The objective of the study was to determine the frequency of various breast diseases in female patients and to analyze the percentage of incidence of breast diseases and different mode of presentation.

\section{Materials and Methods:}

Sample size: A total of 3555 patients diagnosed with breast lesions over a period of ten years in two private clinics were the participants of this study.

\section{Methodology of the study:}

This is a prospective (historical)cohort study carried out at Chittagong Metropoliton Hospital and CSCR (Centre for Specialized care and Research) Hospital over a period of ten years starting from July 2007 to June 2017. All female patients visited with breast problems from 18 to 55 years of age were included in the study. Initially 4147 patients visited with breast problems. Among them 12.23\%(507/ 4147) patients who came mostly with the complaints of 
lumpiness in their breasts and a few of them who came for checkup and found normal both clinically and with imaging were excluded from the study. Another 85 patients were also excluded from the study who were diagnosed as sebaceous cysts in their breasts. So after excluding 592 patients out of 4147, total 3555 patients were included in the study. Detailed history of patients were recorded that included age, marital status, parity, age of last child, breast feeding history and age at menopause. Family history of breast diseases, specially breast cancer, history of contraception used were recorded.

Thorough examination of breast and axilla done. Ultrasonography or mammograms were done according to age. Fine needle aspiration cytology(FNAC) was advised in patients with lump to confirm the diagnosis. Core biopsy/ incision/ excision biopsy was done in patients with inconclusive FNAC report.

The Data were tabulated in excel sheet and analyzed for the frequency of each lesion.

Ethical consideration:

All the patients came to the chamber willingly so ethical consideration was not necessary.

\section{Results:}

A total of 3555 patients from 18 to 55 years were included in the study during the study period from July 2007 to June 2017. Among the patients fibroadenoma was the most common breast disease seen in $32.26 \%(1147 / 3555)$ of patients, followed by mastalgia in $24.22 \%(861 / 3555)$ patients. Fibrocystic disease was seen in $18.80 \%(668 / 3555)$ patients. 7.68\%(273/3555) patients were presented with axillary lump, which were mostly due to accessory axillary breast tissue or lymphadenopathy. 4.59\%(163/3555) patients were visited with breast abscess and acute mastitis, many of them were breast feeding mothers. Most of the patients presented with nipple discharge were diagnosed as a case of duct ectasia, 3.68\%(131/3555), although some young patients had galactorrhoea due to hyperprolactinaemia. $3.49 \%(124 / 3555)$ patients were diagnosed as carcinoma breast. Granulomatous mastitis was not an uncommon entity and 2.19\%(78/3555) patients were diagnosed as granulomatous mastitis and among them 59 were idiopathic granulomatous mastitis and 19 were tubercular mastitis. $1.21 \%(43 / 3555)$ patients had cracked nipple/nipple erosion/ulcer. $0.79 \%(28 / 3555)$ patients came with the complain of their unequal breast size, some of them complained of breast atrophy, some hypertrophy. Some other patients were visited who had lipoma, phyllodes, milk fistula, scar etc. The different spectrum of breast diseases with their frequency are shown in table1.
Table-1

\section{Frequency of breast diseases}

\begin{tabular}{llcc} 
Sl. No & Diseases & Frequency & Percentage \\
\hline 1. & Fibroadenoma & 1147 & 32.26 \\
2. & Mastalgia & 861 & 24.22 \\
3. & Fibrocystic Disease & 668 & 18.80 \\
4. & Axillary lump & 273 & 7.68 \\
5. & Abscess \& mastitis & 163 & 4.59 \\
6. & Duct ectasia & 131 & 3.68 \\
7. & Carcinoma Breast & 124 & 3.49 \\
8. & Granulomatous Mastitis & 78 & 2.19 \\
& (IGM \& TB) & & \\
9. & Cracked Nipple/ Nipple & 43 & 1.21 \\
& erosion/ Nipple ulcer & & \\
10. & Unequal breast size & 28 & 0.79 \\
11. & Others & 39 & 1.10 \\
\hline & Total & 3555 \\
\hline
\end{tabular}

\section{Discussion:}

Lesions that can occur in breast are both benign and malignant. Benign breast diseases constitute a heterogenous group of lesions including developmental anomalies, inflammatory lesions, epithelial and stromal proliferations and neoplasms. Much concern is given to malignant lesions of the breast because it is one of the most common malignancy in women specially in Western countries; however benign lesions are far more frequent than malignant ones ${ }^{4-12}$.

In our study fibroadenoma was the most common BBD seen in 1147 patients, which is $32.26 \%$ of the total 3555 patients. Murillo et al found 38\% incidence of fibroadenoma in a study of about 698 patients with BBD, which is not dissimilar with our study13. Khanzada et al showed 27\% incidence of fibroadenoma in a study of 275 patients 14. Other two studies showed a little higher incidence of $42 \%$ and $45 \%$ respectively ${ }^{15,16}$.

Mastalgia was the second most common (24.22\%) BBD seen in our study but Khanzada et al found $11 \%$ patients with mastalgia. $25 \%$ of the referral to breast clinics in West are due to mastalgia and it affects up to $70 \%$ woman at some times during their lives ${ }^{17}$.

The third most common disease in our study was fibrocystic disease $(18.80 \%)$. In three other studies the frequency was $21 \%, 36 \%$ and $17 \%$ respectively $14,16,15$. Because of low literacy rate and more rural areas, the females affected with fibrocystic disease tend to see a surgeon when the symptoms are alarming. 
In our study a good number of patients (273) were presented with axillary lump, mostly with accessory axillary breast tissue.

The next entity was breast abscess and acute mastitis (163 patients). This was most commonly observed in lactating females during early lactating period. Barton et al found acute bacterial mastitis common at any age but most frequently in lactating breasts ${ }^{18}$.

In our study $3.68 \%$ patients had duct ectasia which can mimic invasive carcinoma clinically ${ }^{19}$. It usually presents with nipple discharge, palpable subareolar mass, pain, nipple inversion or retraction ${ }^{14}$.

In our study 124 patients that is $3.49 \%$ of all breast patients were diagnosed as carcinoma breast. Study showed that the highest incidence of breast cancer was in Northern America and Oceania; and the lowest incidence in Asia and Africa ${ }^{20}$.

Granulomatous mastitis was diagnosed in 78 patients (2.19\%). Among them IGM in 59 patients and Tuberculosis in 19 patients. The term "Idiopathic granulomatous mastitis" is used for granulomatous lesions without an identifiable cause. Identification of etiology requires microbiologic and immunologic testing in addition to histopathologic evaluation 19. In our study we also diagnosed the cases with microbiologic, immunologic and histopathologic testing. Though GM is rare in developed countries, this is not uncommon in Asian countries. The overall incidence is less than $0.1 \%$ of all breast lesions in developed countries and 3-4\% in developing countries ${ }^{21}$.

43 patients presented with cracked nipple, nipple erosion/ ulcer. Most of them were breastfed.

28 patients visited with unequal breast size, some with macromastia and some with atrophy.

Some of the patients presented with other diseases like lipoma, phyllodes, milk fistula etc.

\section{Conclusion:}

Breast diseases are one of the commonest problems in females. Breast cancer is the most common cancer in women worldwide and is the fifth most common cause of death from cancer in women. So much more concern is given for the screening, diagnosis and management of breast cancer. But BBD is far more frequent than malignancy. Our study also showed similar results. In our study fibroadenoma is the commonest breast lesion. Mastalgia is the next common problem. Fibrocystic disease also occurs in a great number of females. It is essential to give importance in assessing these benign lesions to reduce morbidity from those diseases and identify any risk for cancer development.

\section{Referrances:}

1. $\mathrm{Mg} \mathrm{A}, \mathrm{D}$ A, Bhoopal S, Ramanujam R. Benign breast diseases: experience at a teaching hospital in rural India. Int J Res Med Sci. 2013;1(2):73.
2. Naveen N, Mukherjee A, Mahajan V. A clinical study of benign breast disease in rural population. J Evol Med Dent Sci. 2013;2(30):5499-511.

3. Hari S. Shukla SK. Benign breast disorders in non-Western populations:Part II. Benign breast disorder in Indian World J Surg. 1989;13(6):746-9.

4. Caleffi M, Filho DD, Borghetti K et al. Cryoablation of benign breast tumors: evolution of technique and technology. Breast 2004;13:397-407.

5. Kelsey JL, Gammon MD. Epidemiology of breast cancer. Epidemiol Rev 1990;12:228-240.

6. Cole P, Mark Elwood J, Kaplan SD. Incidence rates and risk factors of benign breast neoplasms. Am J Epidemiol 1978;108:112-120.

7. Hutchinson WB, Thomas DB, Hamlin WB et al. Risk of breast cancer in women with benign breast lesion. J Natl Cancer Inst 1980;65:13-20.

8. Fitzgibbons PL, Henson DE, Hutter RV. Benign breast changes and the risk for subsequent breast cancer: an update of the 1985 consensus statement. Cancer Committee of the College of American Pathologists. Arch Pathol Lab Med 1998; 122:1053-1055.

9. Sarnelli R, Squartini F. Fibrocystic condition and "at risk" lesions in asymptomatic breasts: a morphologic study of postmenopausal women. Clin Exp Obstet Gynecol 1991;18:271-279.

10. Bartow SA, Pathak DR, Black WC et al. Prevalence of benign, atypical and malignant breast lesions in populations at different risk for breast cancer. A forensic autopsy study. Cancer 1987;60:2751-2760.

11. Cook MG, Rohan TE. The patho-epidemiology of benign proliferative epithelial disorders of the female breast. J Pathol 1985;146:1-15.

12. La Vecchia C, Parazzini F, Franceschi S et al. Risk factors for benign breast disease and their relation with breast cancer risk. Pooled information from epidemiologic studies. Tumori 1985;71:167-178.

13. Murillo Ortiz B, Botello Hernandez D, Ramirez Mateos C, Reynaga Garcia FJ. Benign breast diseases: clinical, radiological and pathological correlation. Ginecol Obstet Mex 2002;70:613-8.

14. Khanzada TW, Samad A, Sushel C. Spectrum of benign breast diseases: Pak J Med Sci 2009;25(2):265-268.

15. Rashid R, Haq SM, Khan K, Jamal S, Khaliq T, Shah A. Benign breast disorders, a clinicopathological study. Ann Pak Inst Med Sci 2005;1:187-90.

16. Ali K, Abbas MH, Aslam M, Abid KJ, Khan AZ. Frequency of benign breast diseases in female patients with breast lumps- a study at Sir Ganga Ram Hospital, Lahore. Ann King Edward Med Coll 2005;11:526-8.

17. Chaudhary IA, Qureshi SK, Rasul S, Bano A. Pattern of benign breast diseases. J Surg Pak 2003;8:5-7.

18. Barton AS. The Breast. In: Pathology. Rubin E Farber JL. $2^{\text {nd }}$ Edi: Philadelphia: JB Lippincort Co 1994;978.

19. Guray M, Sahin AA. Benign Breast Diseases: Classification, Diagnosis, and Management. The Oncologist 2006;11:435-49.

20. Ferlay J, Soerjomataram I, Ervik M, Dikshit R, Eser S, Mathers C, Rebelo M, Parkin DM, Forman D, Bray, F. GLOBACON 2012 v1.1, Cancer Incidence and Mortality Worldwide: IARC Cancer Base No 11. Lyon, France: International Agency for Research on Cancer; 2014.

21. Hanif A, Mushtaq M, Malik K, Khan A. Tuberculosis of breast. J Surg Pak 2002;7:26-8. 